Published in final edited form as:

J Cell Biochem. 2020 January ; 121(1): 828-839. doi:10.1002/jcb.29328.

\title{
Hypoxia alters the release and size distribution of extracellular vesicles in pancreatic cancer cells to support their adaptive survival
}

\author{
Mary Catherine Patton ${ }^{1,2}$, Haseeb Zubair ${ }^{1,2}$, Mohammad Aslam Khan ${ }^{1,2}$, Seema Sing ${ }^{1,2,3}$, \\ Ajay Pratap Singh $1,2,3,{ }^{*}$ \\ ${ }^{1}$ Mitchell Cancer Institute, University of South Alabama, Mobile, AL 36604 \\ ${ }^{2}$ Department of Pathology, College of Medicine, University of South Alabama, Mobile, AL 36617 \\ ${ }^{3}$ Department of Biochemistry and Molecular Biology, College of Medicine, University of South \\ Alabama, Mobile, AL 36688
}

\begin{abstract}
Pancreatic tumors are highly desmoplastic and poorly-vascularized, and therefore must develop adaptive mechanisms to sustain their survival under hypoxic condition. Extracellular vesicles (EV) play vital roles in pancreatic tumor pathobiology by facilitating inter-cellular communication. Here we studied the effect of hypoxia on the release of EV and examined their role in adaptive survival of pancreatic cancer (PC) cells. Hypoxia promoted the release of EV in PC cell lines, $\mathrm{MiaPaCa}$ and AsPC1, wherein former exhibited a far greater induction. Moreover, a timedependent, measurable and significant increase was recorded for small EV (SEV) in both the cell lines with only minimal induction observed for medium (MEV) and large EV (LEV). Similarly, noticeable changes in size distribution of SEV were also recorded with a shift toward smaller average size under extreme hypoxia. Thrombospondin (apoptotic bodies marker) was exclusively detected on LEV, while Arf6 (microvesicles marker) was mostly present on MEV with some expression in LEV as well. However, CD9 and CD63 (exosome markers) were expressed in both SEV and MEV with a decreased expression recorded under hypoxia. Among all sub-fractions, SEV was the most bioactive in promoting the survival of hypoxic PC cells and HIF-1a stabilization was involved in heightened EV release under hypoxia and for their potency to promote hypoxic cell survival. Altogether, our findings provide a novel mechanism for the
\end{abstract}

\footnotetext{
* Corresponding Author Ajay Pratap Singh, PhD, Professor and Director of Research, Department of Pathology, College of Medicine, Program Leader, Cancer Biology, Mitchell Cancer Institute, University of South Alabama, 1660 Springhill Avenue, Mobile, AL 36604, Tel: +1 251-445-9843, Fax: +1 251-460-6994, asingh@ @ealth.southalabama.edu.

AUTHOR CONTRIBUTION

Idea Conception: APS

Study supervision: APS, HZ

Design of experiments: APS, HZ, MAK, MCP

Development of methodology: APS, MCP, HZ, MAK

Acquisition of data (performed experiments): MCP (Figures 1-4), MAK (Figures 5 \& 6)

Analysis and interpretation of data: APS, MCP, MAK, HZ, SS

Writing, review, and/or revision of the manuscript: HZ, MAK, MCP, SS, APS

DATA AVAILABILITY

All data presented in this manuscript is available for sharing upon a reasonable request.

CONFLICT OF INTEREST

The authors do not have any conflict of interest to report.
} 
adaptive hypoxic survival of PC cells and should serve as the basis for future investigations on broader functional implications of EV.

\section{Keywords}

Pancreatic cancer; Extracellular vesicles; Exosomes; Hypoxia; HIF-1a; tumor microenvironment

\section{INTRODUCTION}

Pancreatic cancer (PC) is one of the most lethal malignancies. It became the third-leading cause of cancer-related death in the United States and its incidence and mortality rates continue to increase with each coming year (Siegel, Miller, \& Jemal, 2018, 2019). Poor clinical outcome of PC is attributed to its delayed diagnosis, aggressive nature and unusual therapeutic resistance (Gnanamony \& Gondi, 2017; Qiu et al., 2018). Difficult clinical management of PC could be explained by its anatomical location, asymptomatic progression, genetic makeup and unique histopathological characteristics (Bhardwaj et al., 2016; Corbo, Tortora, \& Scarpa, 2012; Khan et al., 2017). Pancreatic tumors are highly desmoplastic characterized by extensive deposition of extracellular matrix and poor vasculature (Erkan et al., 2009). As a result, PC cells encounter moderate to extreme hypoxia during the course of their progression, which alter their cellular and behavioral properties (Hidalgo, 2012). In addition, adaptive responses of the PC cells to hypoxia also impact the tumor microenvironment eventually contributing to the aggressive disease progression and therapy resistance (Dauer, Nomura, Saluja, \& Banerjee, 2017; Gnanamony $\&$ Gondi, 2017; He et al., 2016). However, underlying mechanisms remain poorly understood.

Extracellular vesicles (EV) have gained significant attention in recent years as important mediators of inter-cellular communication (Carrasco, Soto-Heredero, \& Mittelbrunn, 2019; Mathieu, Martin-Jaular, Lavieu, \& Thery, 2019). EV are shed by nearly all types of cells and as a proxy of the donor cells they carry their surface molecules and bioactive cellular material (protein, lipids, nucleotides, etc.) (Mathieu et al., 2019; Patel, Patton, Singh, Khushman, \& Singh, 2016; Philley et al., 2017). It has been shown that EV are not only capable of altering the properties of those cells that are in close proximity but also travel to distant sites to have functional consequences by transferring their bioactive cargo (Allenson et al., 2017; Guo et al., 2019). EV are broadly categorized into three major groups (apoptotic bodies, microvesicles and exosomes) based on their biogenesis. Emerging data from our lab and others have shown that EV serve as sensors of the cellular microenvironment changes potentially helping the cells to adjust and respond to the environmental cues (Ban, Lee, Im, \& Kim, 2015; Patel et al., 2017; Samuel et al., 2018).

In the present study, we examined the effect of hypoxia on the release of EV by the pancreatic tumor cells as an adaptive response mechanism. We observed that hypoxia enhances the release and size distribution of EV by pancreatic tumor cells, which have functional significance in promoting their adaptive survival. Mechanistically, we show that HIF-1a plays an important role in altered release of EV and their potency to promote cell 
survival. These data should serve as the leads for future investigations on diverse implications of EV in acute and severe adaptive response of pancreatic tumor cells to hypoxia.

\section{MATERIALS AND METHODS}

\section{Cell lines and reagents}

Pancreatic cancer cell lines (MiaPaCa and AsPC-1) were procured from ATCC (Manassas, VA). Roswell Park Memorial Institute Medium-1660 (RPMI), phosphate buffer saline (PBS), penicillin $(10,000 \mathrm{U} / \mathrm{ml})$, streptomycin $(10,000 \mu \mathrm{g} / \mathrm{ml})$, and trypsin-EDTA were from HyClone Laboratory (Logan, UT); fetal bovine serum (FBS) was from Atlanta Biologicals (Atlanta, GA); extracellular-free FBS was from System BioScience (Palo Alto, CA); antibodies against thrombospondin1, CD9, ARF6, CD63 and HIF-1a were from Abcam (Cambridge, MA); horseradish peroxidase (HRP)-conjugated $\beta$-actin, $\mathrm{CoCl} 2$ and siRNAs against HIF-1A were from Sigma Aldrich (St Louis, MO); anti-mouse or anti-rabbit HRPconjugated secondary antibodies were from Santa Cruz Biotechnology (Santa Cruz, CA); sodium dodecyl sulphate polyacrylamyde gel electrophoresis (SDS-PAGE) reagents and protein DC assay kit were from Bio-Rad (Hercules, CA). Scrambled sequence siRNAs were from Dharmacon (Lafayette, CO); XtremeGene ${ }^{\mathrm{TM}}$ siRNA Transfection Reagent was from Roche (Indianapolis, IN) and phosphatase inhibitor (PPI) cocktail (HALT 100x) was from Invitrogen (Carlsbad, CA).

\section{Cell culture, treatment and transfection}

Cells were maintained as described earlier (Srivastava et al., 2015). Intermittent cell line authentication was done either in-house or commercially by short-tandem repeats (STR) genotyping (Genetica DNA Laboratories, Burlington, NC). For hypoxia treatment, cells were seeded at a density of $1.2 \times 10^{6}$ or $3.5 \times 10^{6}$ in $60 \mathrm{~mm}$ or $100 \mathrm{~mm}$ glass dishes, respectively, and allowed to attach for $24 \mathrm{~h}$. To facilitate cell attachment, glass dishes were pre-incubated with attachment factor $\left(0.1 \%\right.$ gelatin) for $30-60 \mathrm{~min}$ at $37^{\circ} \mathrm{C}$ and attachment factor removed followed by washing with PBS. Media was replaced with fresh RPMI-1640 media supplemented with extracellular vesicles free FBS prior to incubation of cells in hypoxia (moderate; $1.0 \%$, extreme; $0.1 \% \mathrm{O}_{2}$ ). To achieve hypoxia-independent $\mathrm{HIF}-1 \mathrm{a}$ stabilization cells were treated with $\mathrm{CoCl}_{2}(100 \mu \mathrm{M})$ under normoxic culture conditions, HIF-1a stabilization was analyzed by western blotting. Vehicle (PBS) only treatment served as control. For transient transfection, cells were grown to 50-70\% confluence and incubated with $100 \mathrm{nM}$ each of short-interfering RNA (siRNA) against HIF1A (siHIF-1A) or nontargeted scrambled sequence (siScr) for $48 \mathrm{~h}$ using XtremeGene ${ }^{\mathrm{TM}}$ siRNA Transfection Reagent as per manufacturer's instructions.

\section{Isolation of extracellular vesicles from conditioned media}

Conditioned media (CM) from control or treated cells was collected and centrifuged at 300 $\times \mathrm{g}$ for $10 \mathrm{~min}$ to remove cell debris. Thereafter, $\mathrm{CM}$ was subjected to centrifugation at $2,000 \times \mathrm{g}$ for $30 \mathrm{~min}$ to pellet large size $\mathrm{EV}$ (LEV), at 16,500 $\times \mathrm{g}$ for $30 \mathrm{~min}$ to collect moderate size EV (MEV) and 120,000 $\times \mathrm{g}$ for $2 \mathrm{~h}$ to pellet of small EV (SEV) under cold temperature settings $\left(4^{\circ} \mathrm{C}\right)$. 


\section{Size determination of extracellular vesicles by dynamic light scattering (DLS)}

EV sub-fractions collected from normoxic or hypoxic cell were resuspended in deionized water to a final concentration of $0.5 \mu \mathrm{g} / \mu \mathrm{l}$. Then $1 \mu \mathrm{l}$ of resuspended EV sub-fractions was added into $999 \mu \mathrm{l}$ of deionized water (1:1000), transferred into a cuvette and EV size analyzed through Dynamic Light Scattering (DLS or photon correlation spectroscopy) on DelsaMax Pro (Beckman, CA, USA). DLS was measured as the intensity of the light scattered by the suspended particles as a function of time and algorithmically extrapolated as particle hydrodynamic size distribution. To minimize particle interference due to electrostatic forces or collisions, we gently sonicated our diluted samples in a bath sonicator for few seconds before analysis.

\section{Protein quantification and Immunoblotting}

Protein-based quantitation of isolated EV or cell lysates was done using the protein DC assay kit as described earlier (Patel et al., 2019). For immunoblotting, total protein (10/40 $\mu \mathrm{g}$ ) isolated in NP40 buffer supplemented with protease 1X phosphatase inhibitor (PPI) cocktail was loaded on to SDS-Polyacrylamide gel and resolved by electrophoresis. Subsequently, resolved protein bands were transferred on to PVDF membrane and probed with specific antibodies against thrombospondin (THBS1), ARF6, CD9, CD63, HIF-1a and $\beta$-actin. Membranes were incubated with horse radish peroxidase-labelled respective secondary antibodies and signal detected using the SuperSignal west femto maximum sensitivity substrate kit (Thermo Scientific, Logan, UT, USA) on a ChemiDoc Imaging System (Bio-Rad, Hercules, CA).

\section{Cell viability assay}

For cell viability assays, PC cells $\left(1.2 \times 10^{6} /\right.$ dish $)$ were seeded in $60 \mathrm{~mm}$ glass dishes and allowed to adhere overnight. Next day, media was replaced with $5 \%$ vesicle-free media mixed with EV derived from control or treated cancer cells, and cells incubated under extreme hypoxia for different time points $(0-72 \mathrm{~h})$. Cell viability was measured using the Trypan Blue exclusion assay on an automated Countess ${ }^{\circledR}$ cell counter (Invitrogen).

\section{Statistical analysis}

All experiments were performed at least three times and numerical data expressed as mean \pm SD. Wherever appropriate, the data were also subjected to unpaired two-tailed Student's t test or one-way ANOVA. $p<0.05$ was considered statistically significant.

\section{RESULTS}

\section{Hypoxia increases the release of extracellular vesicles from pancreatic cancer cells}

Two well studied pancreatic cancer cell lines, MiaPaCa and AsPC1 (Deer et al., 2010), were incubated under either normoxic or hypoxic (moderate; $1.0 \% \mathrm{O}_{2}$ and extreme; $0.1 \% \mathrm{O}_{2}$ ) culture conditions for $48 \mathrm{~h}$ and conditioned media (CM) collected. After removal of dead cell debris by low speed centrifugation, extracellular vesicles (EV) were isolated by ultracentrifugation and their overall yield determined by protein quantitation. Significant increase in levels of EV was recorded in MiaPaCa cells under both moderate and extreme 
hypoxia; however, it was evident in AsPC1 cells only under extreme hypoxic condition (Fig. 1A). To determine if the hypoxia has similar or differential effect on the release of different EV subtypes, we sub-fractionated them into large (LEV), medium (MEV) and small size vesicles (SEV) by differential centrifugation (as outlined in Supplementary Fig. 1). A greater release of SEV, compared to other EV subtypes, was observed with increasing hypoxia in both the cell lines (Fig. 1B). In subsequent experiments, we studied the release kinetics of all EV subtypes at $12 \mathrm{~h}$ time intervals for $48 \mathrm{~h}$. SEV in MiaPaCa cells under normoxia accumulated in the conditioned media (CM) for up to $24 \mathrm{~h}$ followed by a decrease at later time points. However, under both moderate and extreme hypoxia, their levels kept on increasing in the CM (Fig. 1C, left panel). On the other hand, release of LEV and MEV, although increased, did not significantly differ between normoxia or hypoxia conditions in MiaPaCa cells. In AsPC1 cells, LEV and MEV release remained largely similar under normoxia and hypoxia except for significant difference recorded in MEV release at $24 \mathrm{~h}$. However, release of SEV in these cells continued to increase with the increase of incubation time under both normoxia and hypoxia with significantly greater release recorded under extreme hypoxia condition. Interestingly, SEV release under extreme hypoxia dramatically increased relative to that under moderate hypoxia or normoxia at $12 \mathrm{~h}$ and decreased sharply thereafter with a biphasic rise after $36 \mathrm{~h}$ (Fig. $1 \mathrm{C}$, right panel).

\section{Hypoxia causes a shift in size distribution of released extracellular vesicles}

Having observed variable patterns of release in different sub-fractions of EV from $\mathrm{MiaPaCa}$ and AsPC1 cells, we next analyzed their size distribution using the Dynamic Light Scattering analysis. We observed that size distribution of EV sub-fractions shifted to upper or lower size range in hypoxic conditions and this shift was dissimilar for different subfractions (Fig. 2A and B). In MiaPaCa cells (Fig. 2A), LEV showed a decrease in average size under moderate hypoxia $(616.9 \pm 217.9 \mathrm{~nm})$, which increased somewhat under extreme hypoxia $(751.6 \pm 129.9 \mathrm{~nm})$, compared to that under normoxic condition $(732.6 \pm 198.6 \mathrm{~nm})$. On the other hand, average size of MEV and SEV increased under moderate hypoxia (404.4 $\pm 55.6 \mathrm{~nm}$ and $136.7 \pm 29.5 \mathrm{~nm}$, respectively) and decreased slightly under extreme hypoxia ( $280.5 \pm 51.2 \mathrm{~nm}$ and $98.5 \pm 49.2 \mathrm{~nm}$, respectively), compared to that under normoxia (358.7 $\pm 55.3 \mathrm{~nm}$ and $121.3 \pm 23.8 \mathrm{~nm}$, respectively). In AsPC1 cells (Fig. 2B), LEV exhibited a nominal decrease in average size under both moderate and extreme hypoxia $(919.6 \pm 237.4 \mathrm{~nm}$ and $796.4 \pm 340.2 \mathrm{~nm}$, respectively) compared to that $(949.3 \pm 188.1 \mathrm{~nm})$ under normoxia. However, MEV in these cells showed a slight decrease $(415.7 \pm 80.4 \mathrm{~nm})$ and increase $(471.5 \pm 63.7 \mathrm{~nm})$ under moderate and extreme hypoxia, respectively, compared to normoxia $(465.0 \pm 64.0 \mathrm{~nm})$. Whereas, SEV exhibited an increase $(135.3 \pm 31.9 \mathrm{~nm})$ under moderate hypoxia and a dramatic decrease $(57.9 \pm 24.9 \mathrm{~nm})$ under extreme hypoxia compared to that $(111.8 \pm 48.1 \mathrm{~nm})$ under normoxia. Overall, the most noticeable changes were observed for SEV in both the cell lines under extreme hypoxia (Fig. 2A and B).

\section{Characterization of isolated sub-fractions based on defined markers of apoptotic bodies, microvesicles and exosomes}

In general, most LEV, MEV and SEV should correspond to apoptotic bodies, microvesicles and exosomes, respectively (Mathieu et al., 2019). Therefore, to characterize our isolated sub-fractions from normoxic or hypoxic cells, we probed them for known markers of 
apoptotic bodies (thrombospondin 1, THBS1), microvesicles (Arf6) and exosomes (CD9 and CD63) by immunoblotting using specific antibodies. Data revealed that apoptotic body marker THBS1 was exclusively expressed in LEV population isolated from both the cell lines with the exception of LEV in 1\% $\mathrm{O}_{2}$ of AsPC1 (Fig. 3A and B). Arf6 was predominantly expressed in MEV in both the cell lines, but was also detected on LEV specially in AsPC1 cells (Fig. 3B). CD9 and CD63 were expressed differentially in EV subfractions from the two cell lines (Fig. 3A and B). CD63 appeared either as a smear or multiple bands due to its heavy glycosylation. MEVs from MiaPaCa cells had the highest expression of CD9 under both normoxia and hypoxia, whereas in AsPC1 cells, CD9 expression was greatest in SEVs under normoxia, which then decreased and shifted to MEVs and LEVs with increasing hypoxia (Fig. 3A and B). CD63 was expressed in all subfractions of EVs from MiaPaCa cells under normoxia, but its expression decreased significantly with decreasing oxygen levels (Fig. 3A). In AsPC1 cells, CD63 was mostly expressed on SEV under normoxia, which decreased to negligible levels with increasing hypoxia (Fig. 3B).

\section{Small extracellular vesicles provide the most survival benefit to cancer cells under hypoxia}

Extracellular vesicles have emerged as important mediators of cellular communications that play important role in physiology and pathobiology (Guo et al., 2019; Patel et al., 2017; Taylor \& Gercel-Taylor, 2011). Since we observed an increased release of EV under hypoxia, we evaluated if they have a role in acute survival response of pancreatic cancer cells. MiaPaCa and AsPC1 cells were treated with different sub-fractions of EV isolated from respective cells under normoxia and hypoxia $\left(0.1 \% \mathrm{O}_{2}\right)$ and subjected to hypoxia for $72 \mathrm{~h}$. Growth was monitored at $24 \mathrm{~h}$ time intervals by automated cell counting. We observed that LEV from hypoxic cells provided no survival benefit to pancreatic cancer cells under hypoxia over those derived from normoxic cancer cells. However, hypoxic MEV were able to sustain the growth to some extent in both the cell lines (Fig. 4A and B). Interestingly, we observed that even the MEV from normoxic cells supported the hypoxic growth in AsPC1 cells, when compared to the growth of these cells treated with hypoxic or normoxic LEV (Fig. 4A). In contrast, we observed that SEV from hypoxic cells provided the most noticeable survival benefit in both MiaPaCa and AsPC1 cells (Fig. 4A and B). More importantly, even the SEV from normoxic cells were able to support the survival under hypoxia in AsPC1 cells (Fig. 4B).

\section{Enhanced release and potency to promote hypoxic survival of small extracellular vesicles is dependent on hypoxia inducible factor -1 a stabilization}

Hypoxia inducible factor- $1 a$ is considered a master regulator of the adaptive cellular responses to hypoxia (Semenza, 2000). Therefore, we investigated if it had a role in enhanced release of EV and their effect on hypoxic survival of PC cells. PC cells (MiaPaCa and AsPC1) were treated with either vehicle (PBS) or $\mathrm{CoCl}_{2}$, which stabilizes HIF-1a under normoxic conditions to mimic a hypoxic state. After $6 \mathrm{~h}$ of treatment, HIF-1a stabilization was confirmed by immunoblot analysis in both the PC cell lines (Figure 5A). In parallel experiments, we treated $\mathrm{PC}$ cells with $\mathrm{CoCl}_{2}$ for $48 \mathrm{~h}$ and isolated SEV from the conditioned media. Estimation of exosome yield demonstrated that hypoxia mimetic treatment led to a significant increase in SEV release in both PC cell lines as compared to that observed 
vehicle only treated cells (Figure 5B). Next, we examined the effect of $\mathrm{CoCl}_{2}$-derived SEV on the tumor cell viability under hypoxia. The data demonstrated that SEV derived from $\mathrm{CoCl}_{2}$-treated cells were able to provide a significant survival advantage to pancreatic cancer cells under hypoxia as compared to those derived from vehicle-treated cells (Figure 5C). To further confirm the role of HIF-1a in the release of SEV and their potency to promote hypoxic survival of PC cells, we silenced its expression by RNA interference (Fig. 6A). When these HIF-1a-silenced cells were subjected to hypoxia, a significant decrease in their SEV release capability was detected as compared to the control PC cells that had been transfected with scrambled sequence siRNAs (Fig. 6B). More importantly, these SEVs also lost their potency to provide the survival benefit to the hypoxic PC cells (Fig. 6C).

\section{DISCUSSION}

Cancer cells encounter a variety of microenvironmental stress during their progressive journey (Ackerman \& Simon, 2014; Chen, Bobak, Stasyk, \& Kunz-Schughart, 2018; Cook et al., 2004). Clearly, they must find ways to adapt to these changing environmental pressures to not only sustain their growth, but to evolve to a state of heightened malignancy. In this study, we have generated evidence to suggest an important adaptive survival mechanism for the PC cells under acute hypoxia. Pancreatic cancer is one of the deadliest cancers with unique histopathological characteristics (Neoptolemos et al., 2018). Extensive desmoplasia and poor vasculature make pancreatic tumors highly hypoxic, which is an important reason for their poor clinical outcome (Couvelard et al., 2005; Hoffmann et al., 2008; Mangge et al., 2017). We observed that increasing hypoxia promoted the release of EV by pancreatic tumor cells, and their uptake helped cancer cells survive better under hypoxia. Moreover, we found that stabilization of HIF-1a, an established master regulator of adaptive hypoxic response, was vital for enhanced release of EV and their potency to sustain the hypoxic survival of pancreatic tumor cells.

Extracellular vesicles (EV) are getting increasing recognition as important mediators of cellcell communication. Although initially believed to serve as trash bags to get rid of unwanted cellular material, EV are now established as functional entities that are capable of altering the properties of the recipient cells through transfer of bioactive cargo (Patel et al., 2017; Wang et al., 2018). Furthermore, it has also been demonstrated that their biogenesis and shedding can be influenced by extracellular stimuli, which holds broader functional significance (Ban et al., 2015; Kanchanapally et al., 2019; Patel et al., 2017). In our study, we observed that hypoxic stress stimulated the release of EV by pancreatic tumor cells and the most consistent and noticeable differences were reported for small size EV (SEV). This is similar to our prior observation where chemotherapeutic insult promoted increased shedding of SEV (Kanchanapally et al., 2019; Patel et al., 2017). Interestingly, we also observed cell line-specific differences in the level of induction of EV release. While both $\mathrm{MiaPaCa}$ and AsPC1 cells exhibited increased release of EV under hypoxia, the level of induction was considerably higher in MiaPaCa cells (4.2 fold) as compared to AsPC1 cells (1.6 fold). This could likely be due to the differences in their genetic makeup. MiaPaCa cells harbor a TP53 mutation that result in altered gain-of-function (Deer et al., 2010). On the other hand, TP53 mutation in AsPC1 cells leads to a non-translated gene product (Deer et al., 2010). Since a role of p53 has been reported in the development of EV (Novo et al., 
2018; Sun et al., 2016), it is likely that different p53 mutations and/or other genetic dissimilarities underlie the differential shedding of EV by these two cell lines, which should be investigated in future studies.

Extracellular vesicles are mainly categorized into three groups viz. apoptotic bodies (AB), microvesicles (MV) and exosomes (Exo) (Thery et al., 2018). These EV subtypes, in general, differ in size ranges, of which $\mathrm{AB}$ are the largest (800-5000 $\mathrm{nm}$ diameter), MV medium (50-1000 nm diameter) and smallest of them are Exo (50-150 nm diameter). However, variability in their size exists and their true identity is only defined based on the presence of biomarkers reflecting their distinctive biogenesis (Thery et al., 2018). AB are formed during apoptosis when cells disintegrate into membrane vesicles, whereas MV directly bud off the plasma membranes for not yet clearly understood reasons(Mathieu et al., 2019). Exo, on the other hand, are released when multi-vesicular bodies (MVB) exocytose (Patel et al., 2016). We observed an effect of hypoxic stress on the size distribution of different size-based isolated sub-fractions of EV. Specially, SEV, which exhibited the most heightened release under hypoxia, shifted toward a smaller size distribution ( 19\% and 48\% decrease on an average for MiaPaCa and AsPC1 cells, respectively) under extreme hypoxia $\left(0.1 \% \mathrm{O}_{2}\right)$. Interestingly, a slight increase in size of SEV was observed under moderate hypoxia $\left(1.0 \% \mathrm{O}_{2}\right)$ in both the cell lines. Although underlying reason(s) for this altered size distribution are not clear, one could argue that since under hypoxia metabolites become limiting, smaller size shift could be a strategy of cells to restrict their loss. However, an increased release of EV under hypoxia counters this argument. In additional findings, we observed that while the markers of AB were expressed by the LEV in both the cell lines, there was some overlap between MV marker, ARF6, in MEV and LEV sub-fractions. THBS1, thrombospondin 1, was incidentally found to decrease with increase in hypoxia. Given the fact that THBS1 serves multiple biological functions, it may be the cellular response to hypoxia which leads to the downregulation of THBS1, rather than reduced apoptosis (Bienes-Martinez et al., 2012; Xu et al., 2017). On the other hand, the expression of Exo markers, CD9 and CD63, was detected in all (LEV, MEV and SEV) sub-fractions that varied between sub-fractions and was altered significantly under normoxia and hypoxia. These data could either suggest that under hypoxic stress, a subgroup of EV subtypes exhibit drastic changes in size distribution, or less restrictive expression of the assigned biomarkers. Indeed, there are reports suggesting the existence of larger size Exo in cancer and wider size distribution of MV as well (Antonyak et al., 2011; Meehan, Rak, \& Di Vizio, 2016). Moreover, it is also reported that no biomarker is absolutely specific for any of the EV subtypes (Thery et al., 2018).

Lastly, we also observed that heightened release of EV, especially SEV, had a functional relevance in supporting the hypoxic survival of pancreatic tumor cells. In addition, we found that the increased release and their potency to promote survival was dependent on HIF-1a stabilization. HIF-1a is well established as an important regulator of adaptive cellular responses to hypoxia (Semenza, 2000). Being a transcription factor, it regulates the expression of a variety of genes to promote hypoxia adaptation pathways; both acute and chronic (cell cycle arrest, survival, metabolic switching, angiogenesis, etc.). However, its role in promotion of EV release is not yet established. Furthermore, it is also not yet established how hypoxia influences the EV cargo composition in pancreatic tumor cells to 
impart hypoxic survival benefit. Some studies do suggest for the involvement of HIF-1a in the biological properties imparted by hypoxic EV. For example, EV from hypoxic glioblastoma multiforme (GBM) cells carry Bcl-2 interacting protein 3 (BNIP3) (Kucharzewska et al., 2013). BNIP3 is a HIF-1a responsive gene and has been shown to promote survival via a variety of mechanisms (Burton, Eisenstat, \& Gibson, 2009; Gang et al., 2015). A recent study in pancreatic cancer, however, reported that EV derived from hypoxic tumor cells contained miR-301a, which was involved in M2 macrophage polarization (Wang et al., 2018). In other studies, EV derived from a variety of cancer cells grown under hypoxia are shown to contain miR-21 (Dong et al., 2019; Li et al., 2016), a downstream target of HIF-1a, which plays important roles in hypoxic tumor cell survival (Mace et al., 2013; Polytarchou et al., 2011). Therefore, it is imperative that we investigate the differences in cargo composition of normoxic and hypoxic cell-derived EV. Furthermore, these studies should be expanded in 3-D culture and organoids using patient-derived tissues to more closely mimic in vivo tumor conditions. 3-D culturing of cancer cells has been shown to impact their functional attributes pertaining to cell survival and malignant behavior (DelNero et al., 2015; Volkmer et al., 2008; Whitman, Lin, Kenney, Albertini, \& Lockett, 2019). It may also be helpful in establishing relevant hypoxia gradient that the tumor cell experience in vivo (DelNero et al., 2015). Altogether, our studies provide important novel data to support a novel hypoxia survival mechanism. Future studies are warranted to examine the wider implications of EV derived from hypoxic pancreatic tumor cells to improve clinical management.

\section{Supplementary Material}

Refer to Web version on PubMed Central for supplementary material.

\section{ACKNOWLEDGEMENT}

This work was supported, in part, by funding from NIH/NCI [R01CA175772, and R01CA224306 (to APS)] and USAMCI. The authors would like to acknowledge Dr. Sanjeev Srivastava for his assistance on the manuscript preparation.

\section{REFERENCES}

Ackerman D, \& Simon MC (2014). Hypoxia, lipids, and cancer: surviving the harsh tumor microenvironment. Trends Cell Biol, 24(8), 472-478. doi:10.1016/j.tcb.2014.06.001 [PubMed: 24985940]

Allenson K, Castillo J, San Lucas FA, Scelo G, Kim DU, Bernard V, ... Alvarez H (2017). High prevalence of mutant KRAS in circulating exosome-derived DNA from early-stage pancreatic cancer patients. Ann Oncol, 28(4), 741-747. doi:10.1093/annonc/mdx004 [PubMed: 28104621]

Antonyak MA, Li B, Boroughs LK, Johnson JL, Druso JE, Bryant KL, ... Cerione RA (2011). Cancer cell-derived microvesicles induce transformation by transferring tissue transglutaminase and fibronectin to recipient cells. Proc Natl Acad Sci U S A, 108(12), 4852-4857. doi:10.1073/pnas. 1017667108 [PubMed: 21368175]

Ban JJ, Lee M, Im W, \& Kim M (2015). Low pH increases the yield of exosome isolation. Biochem Biophys Res Commun, 461(1), 76-79. doi:10.1016/j.bbrc.2015.03.172 [PubMed: 25849885]

Bhardwaj A, Srivastava SK, Singh S, Tyagi N, Arora S, Carter JE, ... Singh AP (2016). MYB Promotes Desmoplasia in Pancreatic Cancer through Direct Transcriptional Up-regulation and Cooperative Action of Sonic Hedgehog and Adrenomedullin. J Biol Chem, 291(31), 16263-16270. doi:10.1074/jbc.M116.732651 [PubMed: 27246849] 
Bienes-Martinez R, Ordonez A, Feijoo-Cuaresma M, Corral-Escariz M, Mateo G, Stenina O, ... Calzada MJ (2012). Autocrine stimulation of clear-cell renal carcinoma cell migration in hypoxia via HIF-independent suppression of thrombospondin-1. Sci Rep, 2, 788. doi:10.1038/srep00788 [PubMed: 23145312]

Burton TR, Eisenstat DD, \& Gibson SB (2009). BNIP3 (Bcl-2 $19 \mathrm{kDa}$ interacting protein) acts as transcriptional repressor of apoptosis-inducing factor expression preventing cell death in human malignant gliomas. J Neurosci, 29(13), 4189-4199. doi:10.1523/JNEUROSCI.5747-08.2009 [PubMed: 19339613]

Carrasco E, Soto-Heredero G, \& Mittelbrunn M (2019). The Role of Extracellular Vesicles in Cutaneous Remodeling and Hair Follicle Dynamics. Int J Mol Sci, 20(11). doi:10.3390/ ijms20112758

Chen OI, Bobak YP, Stasyk OV, \& Kunz-Schughart LA (2018). A Complex Scenario and Underestimated Challenge: The Tumor Microenvironment, ER Stress, and Cancer Treatment. Curr Med Chem, 25(21), 2465-2502. doi:10.2174/0929867325666180117110259 [PubMed: 29345569]

Cook JA, Gius D, Wink DA, Krishna MC, Russo A, \& Mitchell JB (2004). Oxidative stress, redox, and the tumor microenvironment. Semin Radiat Oncol, 14(3), 259-266. doi:10.1016/j.semradonc. 2004.04.001 [PubMed: 15254869]

Corbo V, Tortora G, \& Scarpa A (2012). Molecular pathology of pancreatic cancer: from bench-tobedside translation. Curr Drug Targets, 13(6), 744-752. [PubMed: 22458520]

Couvelard A, O'Toole D, Leek R, Turley H, Sauvanet A, Degott C, ... Pezzella F (2005). Expression of hypoxia-inducible factors is correlated with the presence of a fibrotic focus and angiogenesis in pancreatic ductal adenocarcinomas. Histopathology, 46(6), 668-676. doi:10.1111/j. 1365-2559.2005.02160.x [PubMed: 15910598]

Dauer P, Nomura A, Saluja A, \& Banerjee S (2017). Microenvironment in determining chemoresistance in pancreatic cancer: Neighborhood matters. Pancreatology, 17(1), 7-12. doi:10.1016/ j.pan.2016.12.010 [PubMed: 28034553]

Deer EL, Gonzalez-Hernandez J, Coursen JD, Shea JE, Ngatia J, Scaife CL, ... Mulvihill SJ (2010). Phenotype and genotype of pancreatic cancer cell lines. Pancreas, 39(4), 425-435. doi:10.1097/ MPA.0b013e3181c15963 [PubMed: 20418756]

DelNero P, Lane M, Verbridge SS, Kwee B, Kermani P, Hempstead B, ... Fischbach C (2015). 3D culture broadly regulates tumor cell hypoxia response and angiogenesis via pro-inflammatory pathways. Biomaterials, 55, 110-118. doi:10.1016/j.biomaterials.2015.03.035 [PubMed: 25934456]

Dong C, Liu X, Wang H, Li J, Dai L, Li J, \& Xu Z (2019). Hypoxic non-small-cell lung cancer cellderived exosomal miR-21 promotes resistance of normoxic cell to cisplatin. Onco Targets Ther, 12, 1947-1956. doi:10.2147/OTT.S186922 [PubMed: 30881046]

Erkan M, Reiser-Erkan C, Michalski CW, Deucker S, Sauliunaite D, Streit S, ... Kleeff J (2009). Cancer-stellate cell interactions perpetuate the hypoxia-fibrosis cycle in pancreatic ductal adenocarcinoma. Neoplasia, 11(5), 497-508. [PubMed: 19412434]

Gang H, Dhingra R, Lin J, Hai Y, Aviv Y, Margulets V, ... Kirshenbaum LA (2015). PDK2-mediated alternative splicing switches Bnip3 from cell death to cell survival. J Cell Biol, 210(7), 1101-1115. doi:10.1083/jcb.201504047 [PubMed: 26416963]

Gnanamony M, \& Gondi CS (2017). Chemoresistance in pancreatic cancer: Emerging concepts. Oncol Lett, 13(4), 2507-2513. doi:10.3892/ol.2017.5777 [PubMed: 28454427]

Guo Y, Ji X, Liu J, Fan D, Zhou Q, Chen C, ... Sun Z (2019). Effects of exosomes on pre-metastatic niche formation in tumors. Mol Cancer, 18(1), 39. doi:10.1186/s12943-019-0995-1 [PubMed: 30857545]

He X, Wang J, Wei W, Shi M, Xin B, Zhang T, \& Shen X (2016). Hypoxia regulates ABCG2 activity through the activivation of ERK $1 \frac{1}{2} / \mathrm{HIF}-1$ alpha and contributes to chemoresistance in pancreatic cancer cells. Cancer Biol Ther, 17(2), 188-198. doi:10.1080/15384047.2016.1139228 [PubMed: 26785721]

Hidalgo M (2012). New insights into pancreatic cancer biology. Ann Oncol, 23 Suppl 10, x135-138. doi:10.1093/annonc/mds313 [PubMed: 22987949] 
Hoffmann AC, Mori R, Vallbohmer D, Brabender J, Klein E, Drebber U, ... Danenberg PV (2008). High expression of HIF1a is a predictor of clinical outcome in patients with pancreatic ductal adenocarcinomas and correlated to PDGFA, VEGF, and bFGF. Neoplasia, 10(7), 674-679. [PubMed: 18592007]

Kanchanapally R, Deshmukh SK, Chavva SR, Tyagi N, Srivastava SK, Patel GK, ... Singh S (2019). Drug-loaded exosomal preparations from different cell types exhibit distinctive loading capability, yield, and antitumor efficacies: a comparative analysis. Int J Nanomedicine, 14, 531-541. doi: 10.2147/IJN.S191313 [PubMed: 30666112]

Khan MA, Azim S, Zubair H, Bhardwaj A, Patel GK, Khushman M, ... Singh AP (2017). Molecular Drivers of Pancreatic Cancer Pathogenesis: Looking Inward to Move Forward. Int J Mol Sci, 18(4). doi:10.3390/ijms18040779

Kucharzewska P, Christianson HC, Welch JE, Svensson KJ, Fredlund E, Ringner M, .. Belting M (2013). Exosomes reflect the hypoxic status of glioma cells and mediate hypoxia-dependent activation of vascular cells during tumor development. Proc Natl Acad Sci U S A, 110(18), 73127317. doi:10.1073/pnas.1220998110 [PubMed: 23589885]

Li L, Li C, Wang S, Wang Z, Jiang J, Wang W, ... Zhu G (2016). Exosomes Derived from Hypoxic Oral Squamous Cell Carcinoma Cells Deliver miR-21 to Normoxic Cells to Elicit a Prometastatic Phenotype. Cancer Res, 76(7), 1770-1780. doi:10.1158/0008-5472.CAN-15-1625 [PubMed: 26992424]

Mace TA, Collins AL, Wojcik SE, Croce CM, Lesinski GB, \& Bloomston M (2013). Hypoxia induces the overexpression of microRNA-21 in pancreatic cancer cells. J Surg Res, 184(2), 855-860. doi: 10.1016/j.jss.2013.04.061 [PubMed: 23726431]

Mangge H, Niedrist T, Renner W, Lyer S, Alexiou C, \& Haybaeck J (2017). New Diagnostic and Therapeutic Aspects of Pancreatic Ductal Adenocarcinoma. Curr Med Chem, 24(28), 3012-3024. doi:10.2174/0929867324666170510150124 [PubMed: 28494747]

Mathieu M, Martin-Jaular L, Lavieu G, \& Thery C (2019). Specificities of secretion and uptake of exosomes and other extracellular vesicles for cell-to-cell communication. Nat Cell Biol, 21(1), 917. doi:10.1038/s41556-018-0250-9 [PubMed: 30602770]

Meehan B, Rak J, \& Di Vizio D (2016). Oncosomes - large and small: what are they, where they came from? J Extracell Vesicles, 5, 33109. doi:10.3402/jev.v5.33109 [PubMed: 27680302]

Neoptolemos JP, Kleeff J, Michl P, Costello E, Greenhalf W, \& Palmer DH (2018). Therapeutic developments in pancreatic cancer: current and future perspectives. Nat Rev Gastroenterol Hepatol, 15(6), 333-348. doi:10.1038/s41575-018-0005-x [PubMed: 29717230]

Novo D, Heath N, Mitchell L, Caligiuri G, MacFarlane A, Reijmer D, ... Norman JC (2018). Mutant p53s generate pro-invasive niches by influencing exosome podocalyxin levels. Nat Commun, 9(1), 5069. doi:10.1038/s41467-018-07339-y [PubMed: 30498210]

Patel GK, Khan MA, Bhardwaj A, Srivastava SK, Zubair H, Patton MC, ... Singh AP (2017). Exosomes confer chemoresistance to pancreatic cancer cells by promoting ROS detoxification and miR-155-mediated suppression of key gemcitabine-metabolising enzyme, DCK. Br J Cancer, 116(5), 609-619. doi:10.1038/bjc.2017.18 [PubMed: 28152544]

Patel GK, Khan MA, Zubair H, Srivastava SK, Khushman M, Singh S, \& Singh AP (2019). Comparative analysis of exosome isolation methods using culture supernatant for optimum yield, purity and downstream applications. Sci Rep, 9(1), 5335. doi:10.1038/s41598-019-41800-2 [PubMed: 30926864]

Patel GK, Patton MC, Singh S, Khushman M, \& Singh AP (2016). Pancreatic Cancer Exosomes: Shedding Off for a Meaningful Journey. Pancreat Disord Ther, 6(2), e148. doi: 10.4172/2165-7092.1000e148 [PubMed: 27030812]

Philley JV, Kannan A, Griffith DE, Devine MS, Benwill JL, Wallace RJ Jr., ... Dasgupta S (2017). Exosome secretome and mediated signaling in breast cancer patients with nontuberculous mycobacterial disease. Oncotarget, 8(11), 18070-18081. doi:10.18632/oncotarget.14964 [PubMed: 28160560]

Polytarchou C, Iliopoulos D, Hatziapostolou M, Kottakis F, Maroulakou I, Struhl K, \& Tsichlis PN (2011). Akt2 regulates all Akt isoforms and promotes resistance to hypoxia through induction of miR-21 upon oxygen deprivation. Cancer Res, 71(13), 4720-4731. doi:

10.1158/0008-5472.CAN-11-0365 [PubMed: 21555366] 
Qiu J, Yang G, Feng M, Zheng S, Cao Z, You L, ... Zhao Y (2018). Extracellular vesicles as mediators of the progression and chemoresistance of pancreatic cancer and their potential clinical applications. Mol Cancer, 17(1), 2. doi:10.1186/s12943-017-0755-z [PubMed: 29304816]

Samuel P, Mulcahy LA, Furlong F, McCarthy HO, Brooks SA, Fabbri M, ... Carter DRF (2018). Cisplatin induces the release of extracellular vesicles from ovarian cancer cells that can induce invasiveness and drug resistance in bystander cells. Philos Trans R Soc Lond B Biol Sci, 373(1737). doi:10.1098/rstb.2017.0065

Semenza GL (2000). HIF-1: mediator of physiological and pathophysiological responses to hypoxia. J Appl Physiol (1985), 88(4), 1474-1480. doi:10.1152/jappl.2000.88.4.1474 [PubMed: 10749844]

Siegel RL, Miller KD, \& Jemal A (2018). Cancer statistics, 2018. CA Cancer J Clin, 68(1), 7-30. doi: 10.3322/caac.21442 [PubMed: 29313949]

Siegel RL, Miller KD, \& Jemal A (2019). Cancer statistics, 2019. CA Cancer J Clin, 69(1), 7-34. doi: 10.3322/caac.21551 [PubMed: 30620402]

Srivastava SK, Bhardwaj A, Arora S, Singh S, Azim S, Tyagi N, ... Singh AP (2015). MYB is a novel regulator of pancreatic tumour growth and metastasis. Br J Cancer, 113(12), 1694-1703. doi: 10.1038/bjc.2015.400 [PubMed: 26657649]

Sun Y, Zheng W, Guo Z, Ju Q, Zhu L, Gao J, ... Zhao X (2016). A novel TP53 pathway influences the HGS-mediated exosome formation in colorectal cancer. Sci Rep, 6, 28083. doi:10.1038/srep28083 [PubMed: 27312428]

Taylor DD, \& Gercel-Taylor C (2011). Exosomes/microvesicles: mediators of cancer-associated immunosuppressive microenvironments. Semin Immunopathol, 33(5), 441-454. doi:10.1007/ s00281-010-0234-8 [PubMed: 21688197]

Thery C, Witwer KW, Aikawa E, Alcaraz MJ, Anderson JD, Andriantsitohaina R, ... Zuba-Surma EK (2018). Minimal information for studies of extracellular vesicles 2018 (MISEV2018): a position statement of the International Society for Extracellular Vesicles and update of the MISEV2014 guidelines. J Extracell Vesicles, 7(1), 1535750. doi:10.1080/20013078.2018.1535750 [PubMed: 30637094]

Volkmer E, Drosse I, Otto S, Stangelmayer A, Stengele M, Kallukalam BC, ... Schieker M (2008). Hypoxia in static and dynamic 3D culture systems for tissue engineering of bone. Tissue Eng Part A, 14(8), 1331-1340. doi:10.1089/ten.tea.2007.0231 [PubMed: 18601588]

Wang X, Luo G, Zhang K, Cao J, Huang C, Jiang T, ... Qiu Z (2018). Hypoxic Tumor-Derived Exosomal miR-301a Mediates M2 Macrophage Polarization via PTEN/PI3Kgamma to Promote Pancreatic Cancer Metastasis. Cancer Res, 78(16), 4586-4598. doi: 10.1158/0008-5472.CAN-17-3841 [PubMed: 29880482]

Whitman NA, Lin ZW, Kenney RM, Albertini L, \& Lockett MR (2019). Hypoxia differentially regulates estrogen receptor alpha in $2 \mathrm{D}$ and $3 \mathrm{D}$ culture formats. Arch Biochem Biophys, 671, 817. doi:10.1016/j.abb.2019.05.025 [PubMed: 31163125]

Xu X, Song N, Zhang X, Jiao X, Hu J, Liang M, ... Ding X (2017). Renal Protection Mediated by Hypoxia Inducible Factor-1alpha Depends on Proangiogenesis Function of miR-21 by Targeting Thrombospondin 1. Transplantation, 101(8), 1811-1819. doi:10.1097/TP.0000000000001501 [PubMed: 28737660] 


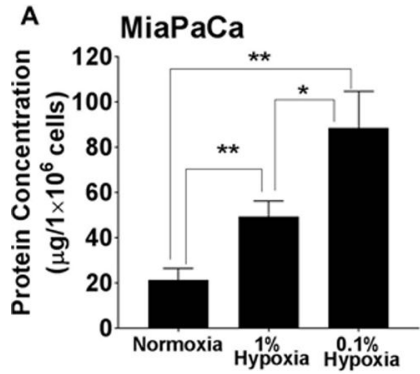

C. MiaPaCa

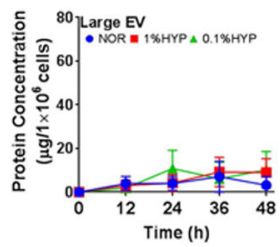

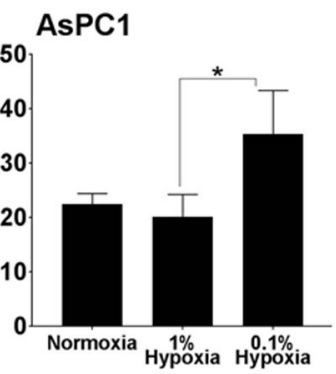

B.
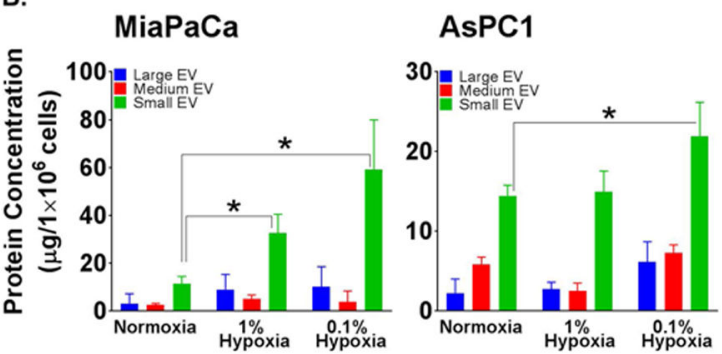

D. AsPC1
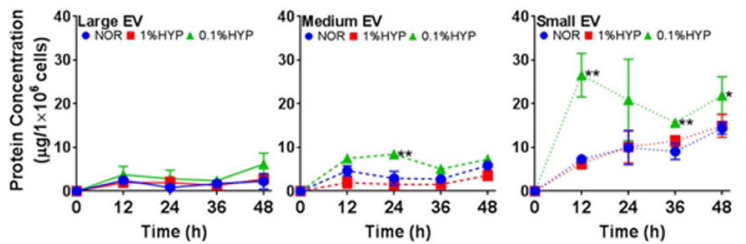

Figure 1. Hypoxia increases the release of extracellular vesicles (EV) from pancreatic cancer cells.

(A) Conditioned media from pancreatic cancer cells (MiaPaCa and AsPC1) cultured under normoxia and hypoxia (moderate, $1.0 \% \mathrm{O}_{2}$; extreme, $0.1 \% \mathrm{O}_{2}$ ) for $48 \mathrm{~h}$, was collected and total EV isolated by ultracentrifugation $(120,000 \mathrm{~g}$ for $2 \mathrm{~h})$. (B) Differential

ultracentrifugation was performed to isolate size-based sub-fractions of EV (large, $2000 \mathrm{~g} \times$ 30min; moderate, $16500 \mathrm{~g} \times 30 \mathrm{~min}$; small 120,000 $\times 120 \mathrm{~min})$. (C) To examine the release kinetics, cells were incubated under normoxia or hypoxia $\left(1.0 \% \mathrm{O}_{2} ; 0.1 \% \mathrm{O}_{2}\right)$ for $0-48 \mathrm{~h}$ and EVs sub-fraction isolated at $12 \mathrm{~h}$ time intervals. In all experiments, EV pellets were suspended in equal volume of PBS and EV release estimated by measuring the protein concentration. Data is presented as mean \pm S.D. of biological replicates. 


\section{A. MiaPaCa}
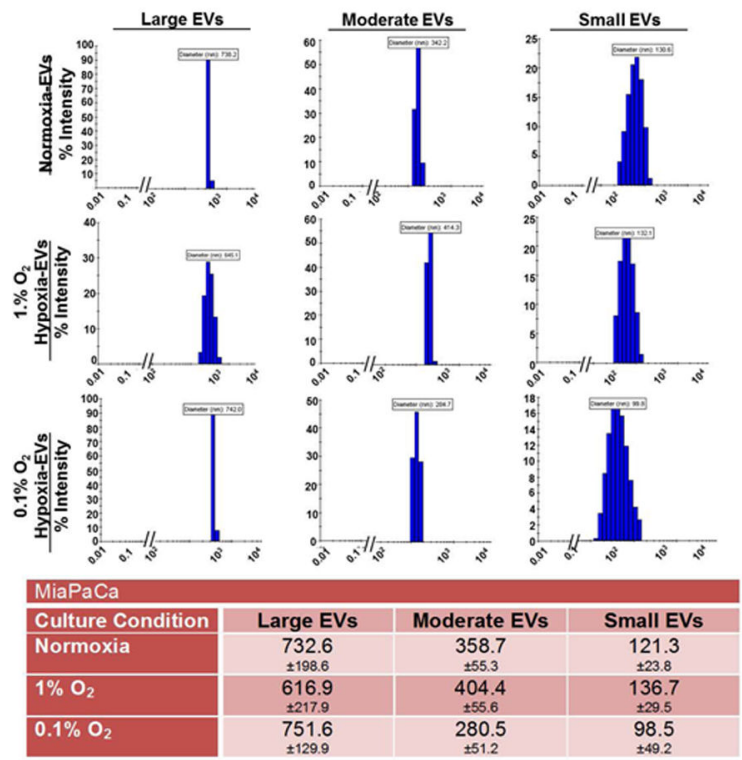

\section{B. AsPC1}
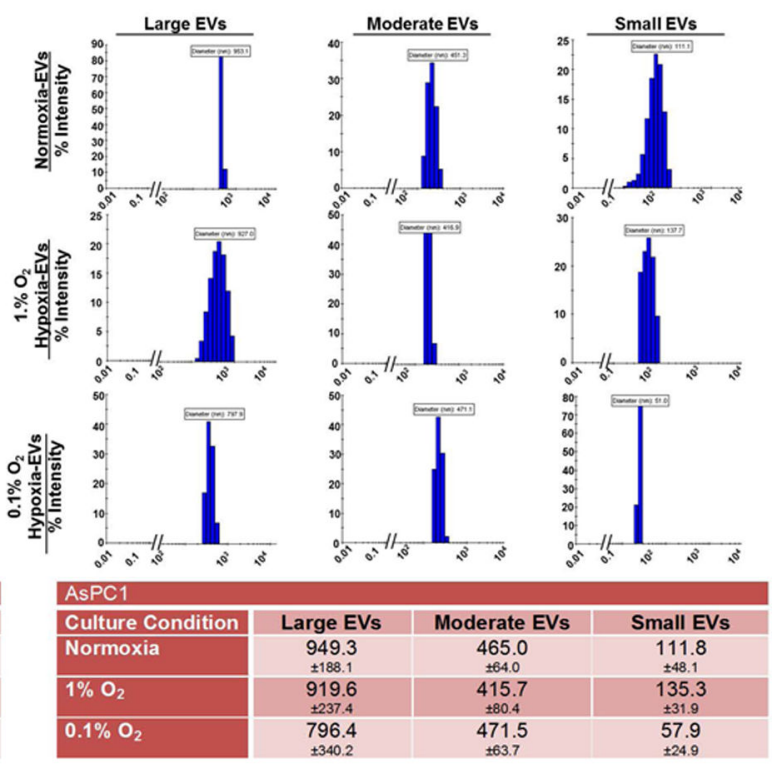

Figure 2. Size distribution analysis of different extracellular vesicles (EV) sub-fractions by dynamic light scattering.

EV sub-fractions were isolated from (A) MiaPaCa and (B) AsPC1 cells cultured under normoxia or hypoxia $\left(1.0 \%\right.$ and $0.1 \% \mathrm{O}_{2}$ ) for $48 \mathrm{~h}$. Freshly isolated $\mathrm{EV}$ were re-suspended in PBS and their hydrodynamic diameters (in $\mathrm{nm}$ ) recorded on a zeta-sizer. Data is presented as mean \pm S.D. from ten readings. 
A.

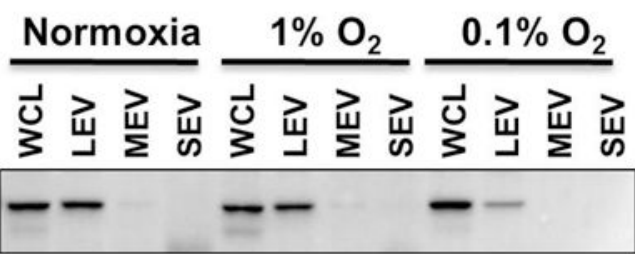
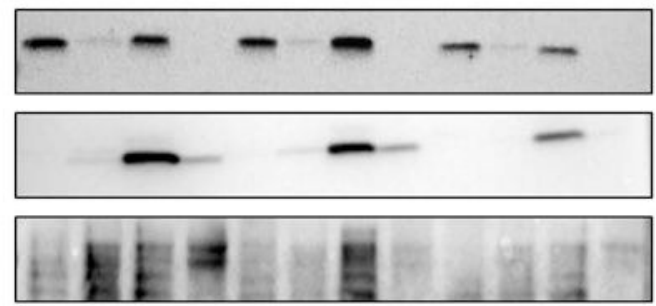

\section{AsPC1} Normoxia $\frac{1 \% \mathrm{O}_{2}}{0.1 \% \mathrm{O}_{2}}$

B.
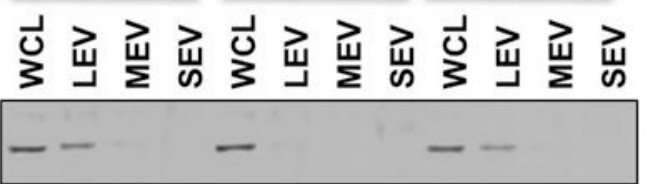

THBS1

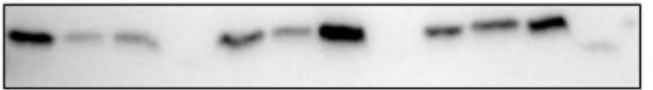

Arf6

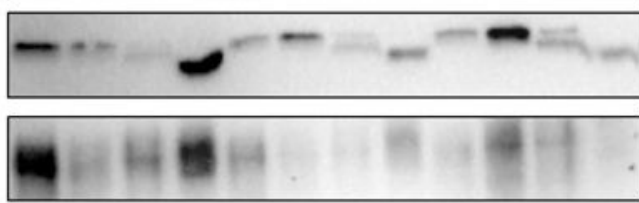

CD9

CD63

Figure 3. Expression of protein markers of apoptotic bodies, microvesicles and exosomes in different EV sub-fractions.

Total protein was isolated from different $\mathrm{EV}$ sub-fractions collected from conditioned media of (A) MiaPaCa and (B) AsPC1 cells grown under normoxia or hypoxia (1.0\% and $0.1 \%$ $\mathrm{O}_{2}$ ) for $48 \mathrm{~h}$. Following quantification, equal amount of proteins were resolved on SDSPAGE, blotted on a PVDF membrane and probed by antibodies specific for different marker proteins (THBS1, apoptotic bodies; Arf6, microvesicles; CD9 and CD63, exosomes). (WCL: whole cell lysate, THBS1: thrombospondin) 


\section{A. MiaPaCa}
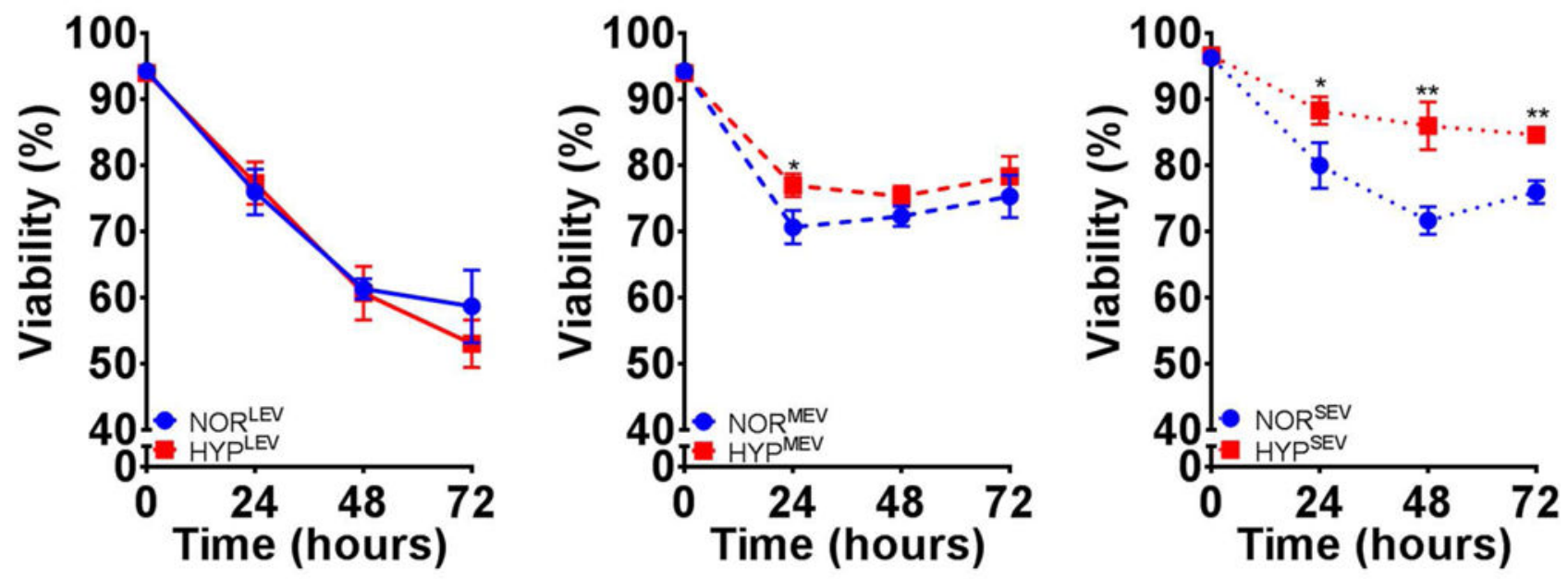

\section{B. AsPC1}
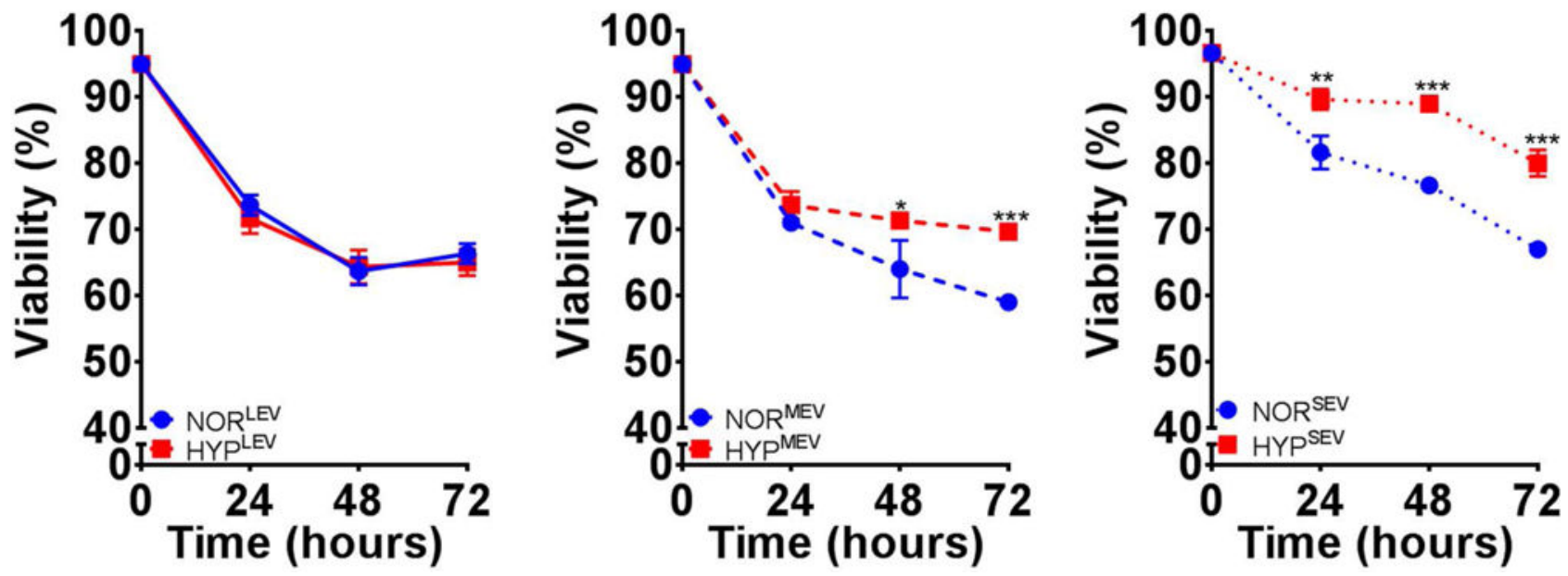

Figure 4. Small extracellular vesicles (EV) are the most potent in providing the survival benefit to pancreatic cancer cells under hypoxia.

Different EV sub-fractions collected from (A) MiaPaCa and (B) AsPC1 cells cultured under normoxia or hypoxia $\left(0.1 \% \mathrm{O}_{2}\right)$ were used to treat cancer cells under hypoxia $\left(0.1 \% \mathrm{O}_{2}\right)$ and their effect on cell viability measured by trypan blue dye exclusion assay. $\mathrm{NOR}^{\mathrm{LEV}}$;

$\mathrm{NOR}^{\mathrm{MEV}}$; NOR ${ }^{\mathrm{SEV}}$ and HYP ${ }^{\mathrm{LEV}}$; HYPMEV; HYPSEV represent large, moderate and small sized EVs from cells cultured under normoxia and hypoxia, respectively. 
A

MiaPaCa

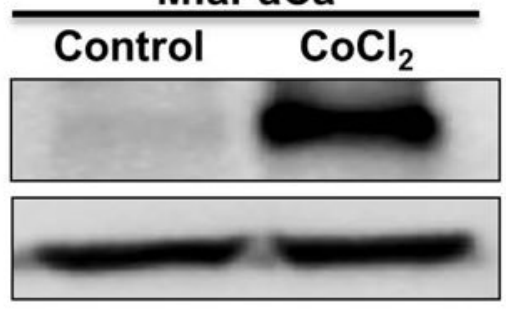

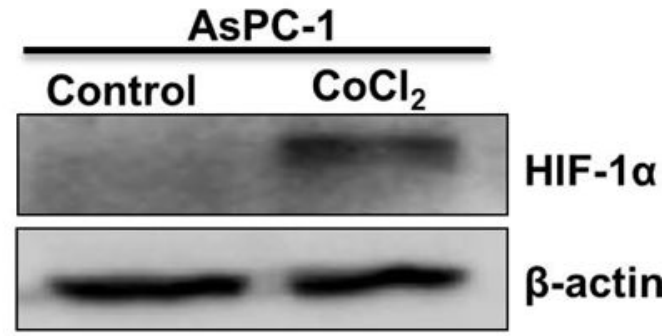

B
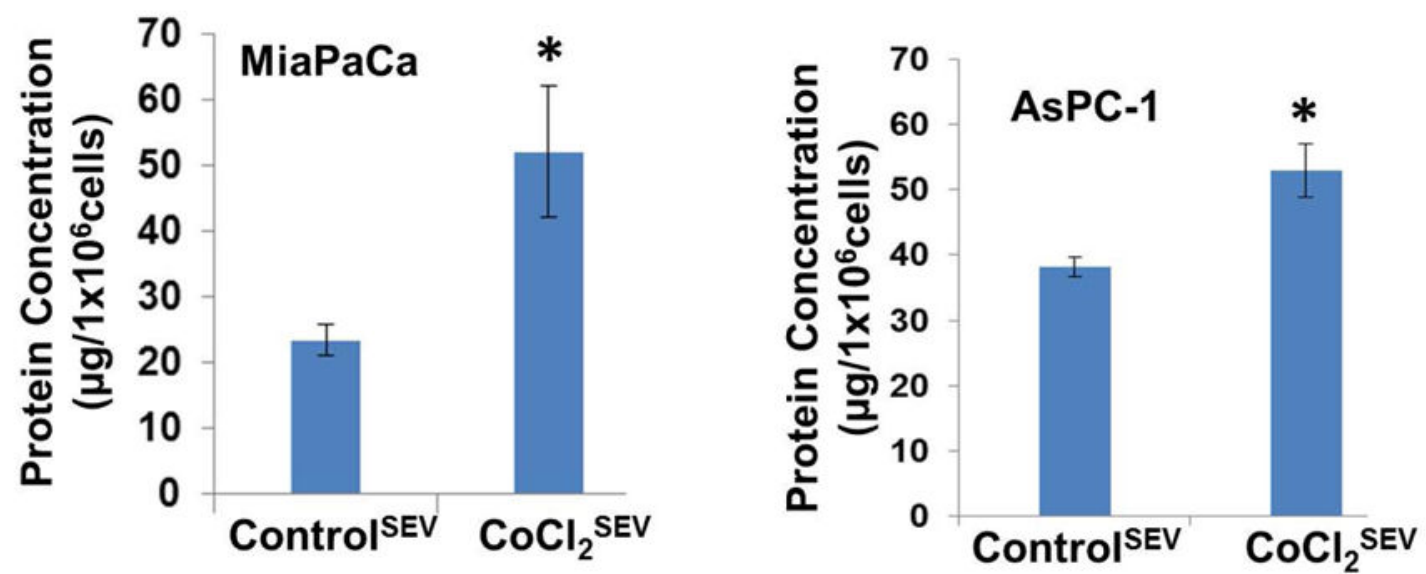

C
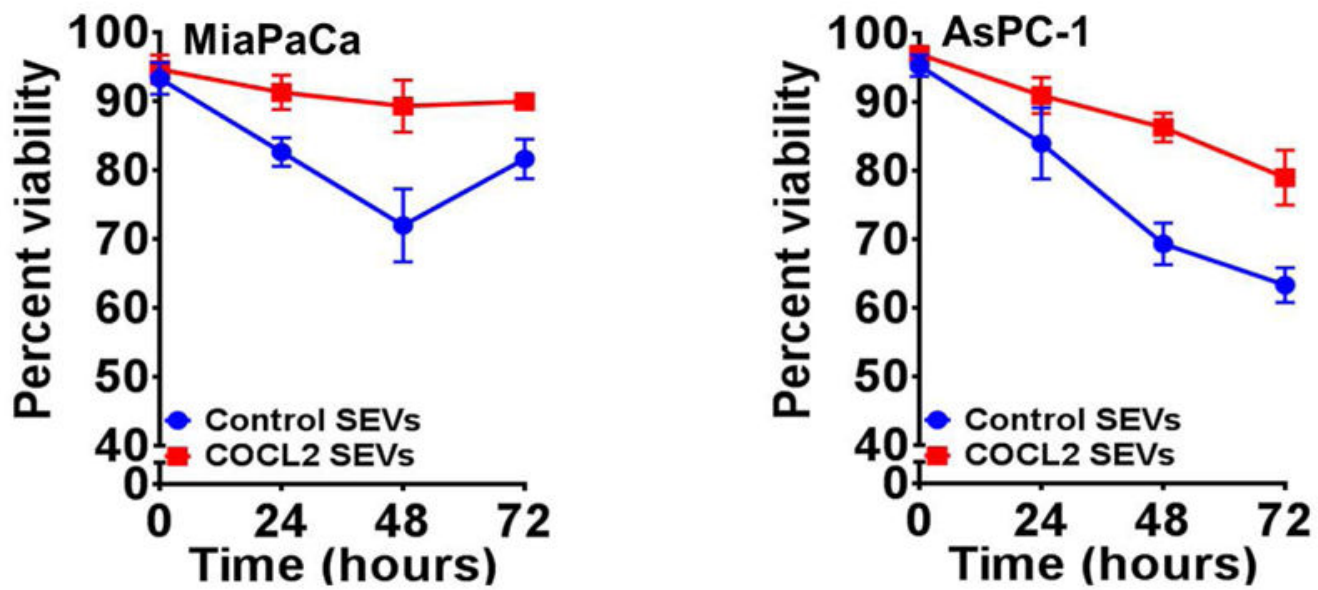

Figure 5. Effect of hypoxia mimetic agent, cobalt chloride, on the release of extracellular vesicles (EVs) and their effect on pancreatic tumor cell viability under hypoxia.

(A) Pancreatic cancer cells were treated with vehicle or $\mathrm{CoCl}_{2}(100 \mu \mathrm{M})$ for $6 \mathrm{~h}$ and total protein isolated. Expression of HIF-1a was examined in treated cells by immunoblotting. $\beta$ actin served as a loading control. (B) Conditioned media from cells treated with either vehicle or $\mathrm{CoCl}_{2}(100 \mu \mathrm{M})$ was collected after $48 \mathrm{~h}$ and small EVs isolated by ultracentrifugation. EV release was estimated by measuring the protein concentrations. (C) Small $\mathrm{EV}$ collected from MiaPaCa and AsPC1 cells treated either with vehicle or $\mathrm{CoCl}_{2}(100 \mu \mathrm{M})$ 
were used to examine their effect on survival of hypoxic cells $\left(0.1 \% \mathrm{O}_{2}\right)$. Viability was measured at $24 \mathrm{~h}$ time-intervals up to $72 \mathrm{~h}$. Data presented is mean \pm S.D. from three replicates. 
A
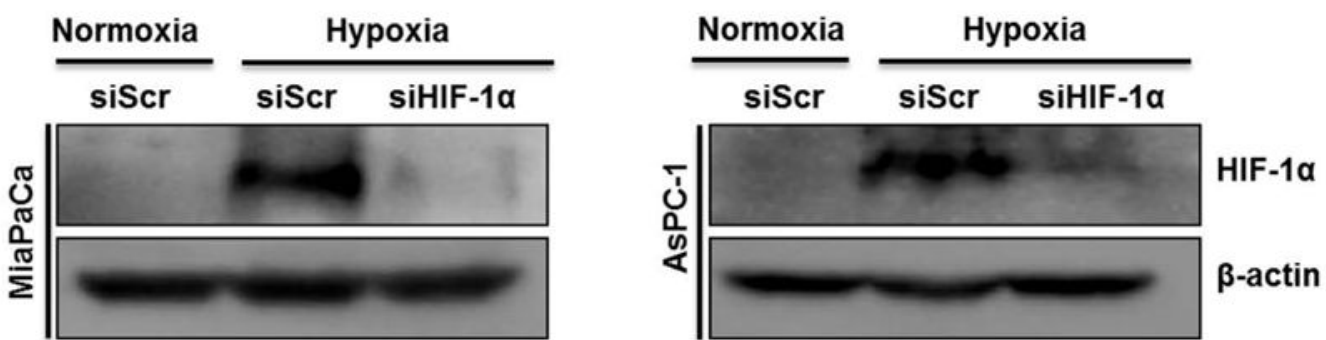

B
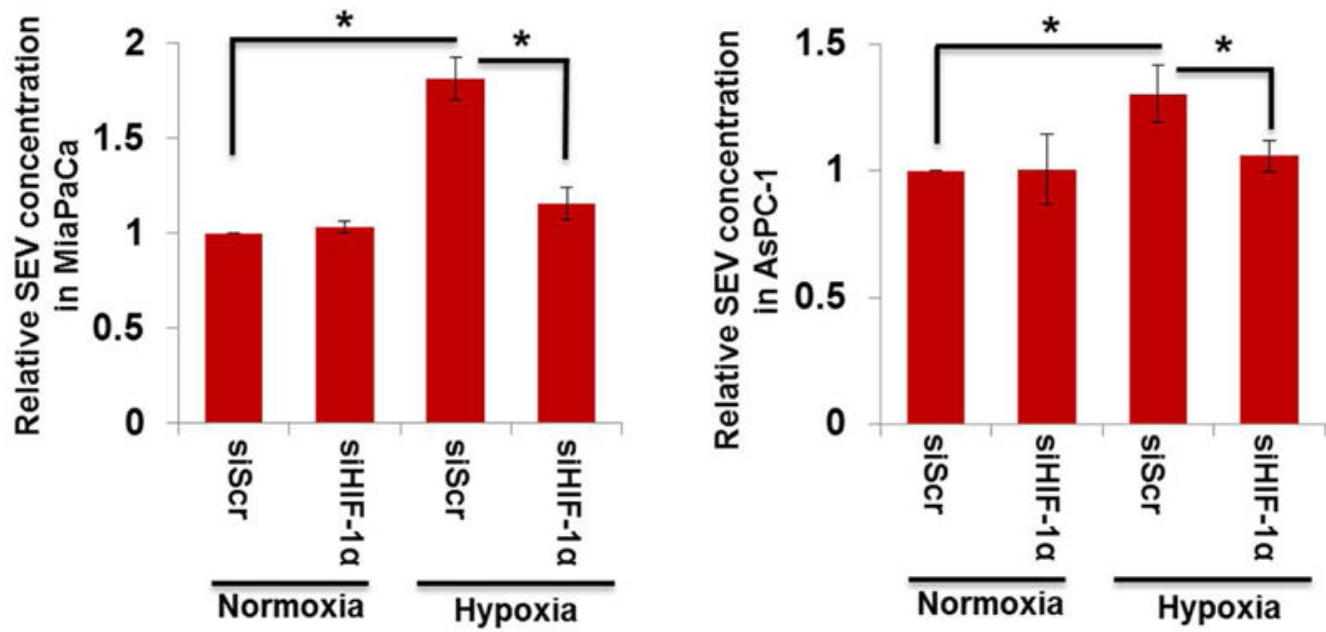

C

MiaPaCa
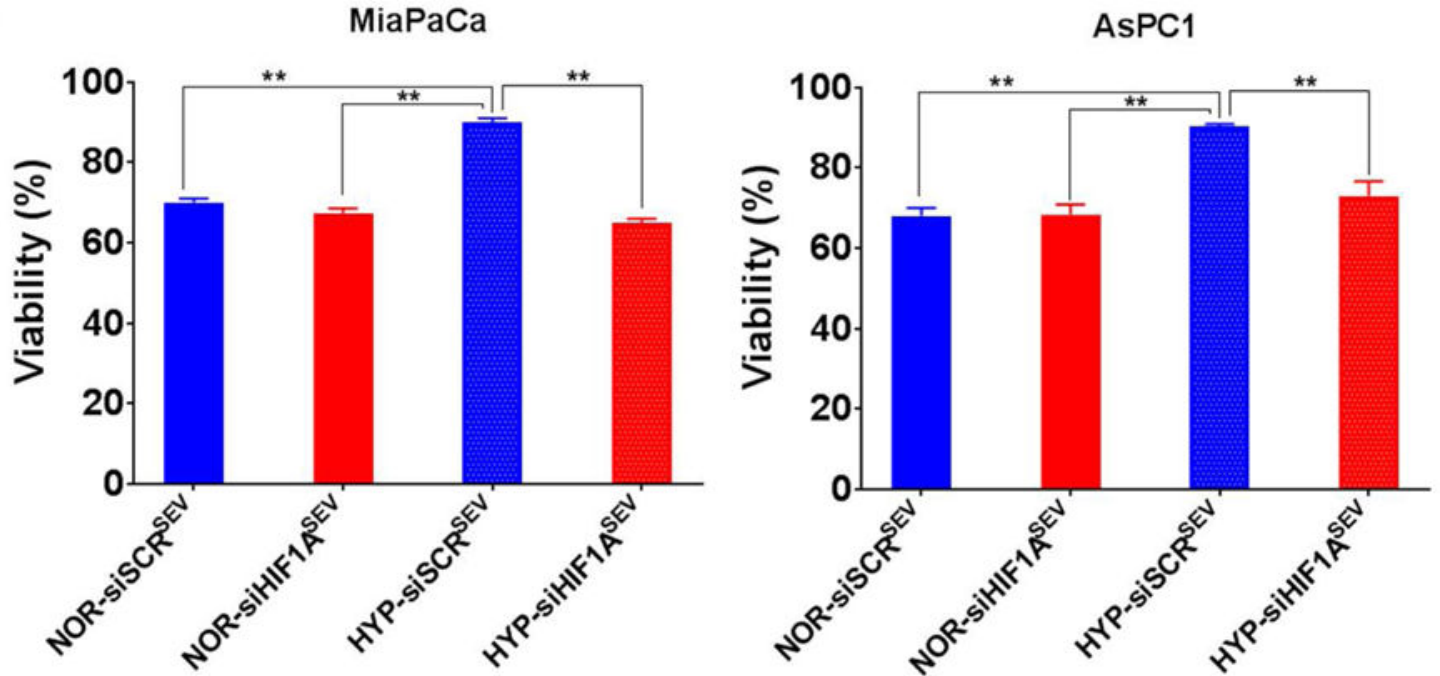

Figure 6. HIF-1a mediates the effect of hypoxia on the release of extracellular vesicles (EV) and their effect on hypoxic survival of pancreatic cancer cells.

(A) Pancreatic cancer cells were transiently transfected for $24 \mathrm{~h}$ with either scrambled (siScr) or HIF-1a (siHIF-1A)-targeting siRNA prior to incubation under hypoxia $\left(0.1 \% \mathrm{O}_{2}\right)$ for 6h. HIF-1a silencing was confirmed by immunoblotting. (B) Small EVs were isolated from control or HIF-1A-silenced cells after incubation either normoxia or hypoxia and their yield measured by protein quantitation. (C) Small EV collected from siScr and siHIF-1A treated $\mathrm{MiaPaCa}$ and $\mathrm{AsPC} 1$ cells cultured in normoxia or hypoxia were used to examine the 
effect on survival of hypoxic cells $\left(0.1 \% \mathrm{O}_{2}\right)$ at $48 \mathrm{~h}$. Data is presented as mean \pm S.D. from three replicates. 